\title{
Financeirização e governança corporativa: Um estudo sobre a estrutura de controle das empresas não-financeiras do Novo Mercado da BM\&FBovespa
}

\author{
Bernardo Pádua Jardim de Miranda* \\ Marco Aurélio Crocco ${ }^{\dagger}$ \\ Fabiana Borges dos Santos ${ }^{\ddagger}$
}

\begin{abstract}
Resumo
O processo de financeirização tem afetado a governança das empresas não-financeiras, pois impõe a convergência das firmas ao modelo anglo-saxão de propriedade dispersa, maximizadora de riqueza ao acionista. Para entender como a financeirização tem afetado a governança das empresas não-financeiras deve-se conhecer sua estrutura de propriedade e controle. O objetivo deste artigo é apresentar a estrutura de controle das empresas nãofinanceiras do Novo Mercado (NM) da BM\&FBovespa no ano de 2012. A amostra é composta por 118 empresas não-financeiras e, a estrutura de controle foi aberta para trás até encontrar o último e os três últimos acionistas. Os resultados mostraram que as famílias e os indivíduos são os principais acionistas, mas houve um aumento da participação dos investidores institucionais, bem como uma redução na concentração do controle da propriedade.

Palavras-chave: Financeirização, Governança Corporativa; Controle da Propriedade.
\end{abstract}

\begin{abstract}
The financialization process has affected the governance of non-financial corporations as it imposes the firms convergence to the Anglo-Saxon model of dispersed property which maximizes the shareholder value. To understand how financialization has affected the governance of non-financial corporations it is important to know their structure and control ownership. The objective of this paper is to present the non-financial companies control ownership in the New Market (NM) of BM\&FBovespa in 2012. The sample is composed of 118 non-financial companies and the control structure was opened backwards until finding the last one and the last three shareholders. The results showed that families and individuals are the main shareholders, but there was an increase in the institutional investors participation, as well as a concentration reduction of the control structure ownership.
\end{abstract}

Key-words: Financialization, Corporate Governance; Control Ownership.

JEL classification: G3; G32 e D23

\footnotetext{
* Professor Adjunto do ICSA/UNIFAL-MG e doutor em Economia pelo CEDEPLAR/UFMG.

${ }^{\dagger}$ BDMG e Professor da FACE/CEDEPLAR/UFMG.

${ }^{\ddagger}$ Pesquisadora do CEDEPLAR/UFMG.
} 


\section{Introdução}

Nas últimas décadas tem-se observado uma subordinação da atividade produtiva às finanças. Esse fenômeno, denominado pelos regulacionistas franceses de financeirização, pode ser interpretado como uma nova forma de regulação e acumulação da economia, por atribuir um papel determinante às variáveis financeiras e aos rendimentos financeiros nas decisões de investimento produtivo e na produção.

O processo de financeirização tem afetado a estrutura de capital, de controle, de propriedade e a governança das empresas não financeiras (Crotty, 2003 e Plihon, 2005). Tem ocorrido um aumento da participação dos investidores institucionais como os principais acionistas nas economias mais desenvolvidas, principalmente dos fundos de investimento. Estes investidores impõem uma governança mais focada na criação de riqueza ao acionista (Boyer, 2000; Aglietta, 2000), resultando na mudança da gestão das empresas de "reter e investir" para "downsizing e distribuir" (Lazonick e O'Sullivan, 2000). Isso implica no crescimento das atividades financeiras, na mudança do perfil do investidor de capital paciente - que busca resultados de longo prazo - para capital impaciente - que busca resultados de curto prazo, no aumento da recompra de ações e da distribuição de lucros e dividendos, e no crescimento mais lento do imobilizado (Stockhammer, 2004; Orhangazi, 2007; Lazonick, 2012; Davis, 2013).

A literatura dominante sobre boas práticas de governança corporativa (GC) é voltada para uma estrutura de controle dispersa e para a criação de riqueza ao acionista. O mercado de capitais é tido como o principal mecanismo de resolução dos problemas de controle e coordenação, exercendo eficientemente uma pressão disciplinadora sobre as firmas (market for corporate control). Supondo mobilidade de capitais, em um mundo econômico e financeiramente liberalizado, o mercado de capitais "forçaria" a convergência das firmas nacionais ao "golden standard" - modelo anglo-saxão de propriedade dispersa, maximizadora de valor para o acionista e caracterizado pelo market for corporate control - considerado o mais eficiente (Chang, 2005).

Para entender como a financeirização tem afetado a governança das empresas nãofinanceiras deve-se conhecer sua estrutura de propriedade e controle, pois a governança pode se diferenciar de acordo com o grau de concentração da propriedade e controle das empresas. Em algumas economias, a estrutura de propriedade é dispersa, não havendo um acionista controlador (caso dos países anglo-saxões), em outras ela é concentrada, havendo um acionista controlador que tende a ser o fundador da empresa, uma família, um indivíduo ou outras corporações que atuam através de uma holding (MAHER e ANDERSSON, 1999). O tipo de estrutura de propriedade e de controle está na origem dos principais problemas de governança. Se a estrutura é dispersa (capitalismo disperso) o problema decorre da relação de agência entre o gestor e os acionistas externos. Se a estrutura é concentrada (capitalismo oligárquico) os problemas, como a expropriação e o tunneling, ocorrem entre o bloco controlador e os minoritários (Coffee Jr., 2001).

A economia brasileira não ficou fora deste processo. As privatizações, a desregulamentação e a liberalização do mercado de capitais afetaram o perfil dos principais acionistas das empresas não-financeiras (Gorga, 2009). O desenvolvimento de novos segmentos no mercado de capitais brasileiro em 2000 (Nível 1, Nível 2 e Novo Mercado) ${ }^{1}$

\footnotetext{
1 O Nível 1 representa o nível mais baixo de governança, seguido pelo Nível 2 e o NM. Esses segmentos impõem uma série de condutas às empresas para transacionar as suas ações. Os critérios para classificação nestes níveis de governança envolvem a manutenção da liquidez dos títulos negociados no mercado de capitais através de uma circulação mínima de ações; mecanismos de oferta pública que
} 
objetiva desenvolver um ambiente institucional que proteja os acionistas minoritários e alinhar as práticas de governança das empresas do mercado de capitais ao padrão internacional, principalmente o anglo-saxão, considerado o mais eficiente.

O objetivo deste artigo é apresentar as estruturas de propriedade e controle das empresas não-financeiras do Novo Mercado (NM) da BM\&FBovespa para o ano de 2012. Para isto, a estrutura acionária dessas empresas foi aberta para trás até encontrar o último principal acionista e os três principais acionistas. Esse segmento de mercado foi escolhido por ser o que mais se aproxima das boas práticas de governança internacional.

Alguns trabalhos empíricos foram realizados para determinar a estrutura de propriedade e controle das empresas não-financeiras brasileiras, destacando-se Siqueira (1998), Aldrighi e Mazzer Neto (2005 e 2007), Gorga (2009) e Cueto (2013). Desses, apenas Gorga (2009) separa as empresas entre os diferentes níveis de governança da BM\&FBovespa (mercado tradicional, N1, N2 e NM). Esses trabalhos buscaram compreender a concentração do capital e o perfil dos acionistas, sem, entretanto, analisar sua relação com a financeirização. Além de analisar uma amostra maior devido ao aumento do número de empresas no NM, o presente artigo inova ao buscar entender se o aprofundamento da financeirização na economia brasileira afetou a estrutura de propriedade e controle das empresas nãofinanceiras.

Os resultados mostram que as famílias e os indivíduos são os principais acionistas das empresas não-financeiras brasileiras. Porém, comparando com os trabalhos de Siqueira (1998), Aldrighi e Mazzer Neto (2005 e 2007) e Gorga (2009), observou-se um aumento da participação de investidores institucionais, principalmente dos fundos de investimento, bem como a redução do número de empresas controladas pelo governo. Além disto, houve uma redução da concentração da propriedade e do controle e, ao contrário do observado por esses autores, a maioria das empresas da amostra não possui um acionista controlador.

Essas mudanças podem decorrer da adoção das práticas de governança defendidas pelo capital financeiro, consideradas por esse como "melhores práticas de governança", principalmente da política de 'uma ação, um voto'. Essa é considerada pelos manuais de boas práticas de governança da Organização para Cooperação e Desenvolvimento Econômico (OCDE) e pelo artigo seminal de Shleifer e Vishny (1996) uma das práticas mais importantes. Portanto, os resultados encontrados revelam indícios de um aprofundamento do processo de financeirização da economia brasileira.

O artigo está dividido em três partes, além desta introdução e da conclusão. A segunda parte discute o conceito de financeirização e as características desse processo na economia brasileira. A terceira parte discute a relação entre estrutura de controle e os problemas de governança, além de resgatar os principais trabalhos empíricos para a economia mundial e brasileira sobre estrutura de controle. A quarta parte apresenta uma análise empírica sobre a estrutura de controle das empresas do NM da BM\&FBovespa para o ano de 2012.

\section{A Financeirização e seus Impactos sobre a Governança das Empresas Não-Financeiras}

Nas últimas quatro décadas houve um aprofundamento do processo de financeirização nos países mais desenvolvidos e em desenvolvimento (Bonizzi, 2013). Não existe ainda na literatura um consenso sobre a definição do termo "financeirização", porém sua concepção envolve os seguintes elementos, como apontado por Stockhammer (2004): a globalização dos mercados; o movimento de maximização da riqueza dos acionistas, o que afeta a gestão das

favoreçam a dispersão do capital; mecanismos de proteção ao acionista minoritário; normas para elaboração de informações econômicas e financeiras; soluções de conflitos, entre outros. 
firmas, priorizando os resultados de curto prazo em detrimento dos de longo prazo; e o aumento da renda das atividades financeiras.

A gênese do processo de financeirização está associada às mudanças no sistema monetário internacional na década de 1960 e às alterações institucionais de ordem micro e macroeconômica a partir dos anos 1970 . O processo de acumulação das economias capitalistas foi modificado pelo fim do sistema de Bretton Woods, que levou à mudança do padrão monetário internacional, juntamente com a aceleração da inflação nos Estados Unidos, o primeiro choque do petróleo, o processo de "estagflação", o aumento da taxa de juros norteamericana e a crise do keynesianismo. Como discutido por Boyer (2009), com o alinhamento aos preceitos monetários e neoliberais houve uma mudança do quadro institucional ${ }^{2}$ vigente na economia, no sentido de se valorizar a estabilização dos preços e promover a liberalização financeira. Além disto, outros fatores contribuíram para a intensificação deste processo, tais como: inovações na tecnologia de informação; criação de novos produtos financeiros (hedge e derivativos) e o surgimento dos investidores institucionais (fundos de pensão, companhias de seguro e clubes de investimento, dentre outros). Segundo Tavares e Melin (1997), a financeirização marca o retorno da hegemonia norte-americana e do dólar como unidade monetária padrão.

Chesnais (1996) define a financeirização como um regime de acumulação "patrimonial", onde "patrimônio" significa a posse de ativos, financeiros e de capital, acumulados e direcionados para o rendimento. Esse processo modifica o significado da riqueza, antes associado à posse de ativos reais e imobilizados, e agora relacionado à posse de ativos financeiros e de moeda, com impactos sobre a estrutura patrimonial de todos os agentes da economia (Aglietta, 2000).

Boyer (2000) define a financeirização como a supremacia das finanças, uma nova força que direciona e molda a acumulação do capital nas economias capitalistas, possivelmente, sucessora do processo de acumulação da Era Fordista ${ }^{3}$. Esse fenômeno pode ser interpretado como uma nova forma de regulação, atribuindo um papel determinante às variáveis financeiras e aos rendimentos financeiros nas decisões de investimento e produção ${ }^{4}$.

Para Stockhammer (2004), a financeirização refere-se ao aumento das atividades financeiras das empresas não financeiras e a uma governança corporativa voltada à criação de riqueza ao acionista ${ }^{5}$. A imposição dessa forma de governança pode reduzir os gastos com a

\footnotetext{
2 De acordo com Boyer (2009) o quadro institucional que prevaleceu na economia entre o fim da segunda guerra mundial e os anos de 1970 estava apoiado nos seguintes pontos: sistema financeiro administrado, relação salarial fordista e políticas macroeconômicas voltadas à manutenção do pleno emprego. $\mathrm{O}$ sistema financeiro administrado mantinha as atividades rentistas sob controle e baixo custo do capital, favorecendo o investimento produtivo via endividamento bancário (a principal função do sistema financeiro era fornecer crédito à atividade produtiva). Esse quadro institucional propiciou um longo período de estabilidade e crescimento econômico.

${ }^{3}$ De acordo com Boyer (2009), há um consenso entre os economistas sobre o fim do processo de acumulação fordista, mas não sobre qual é seu sucessor. Para os regulacionistas franceses, o novo processo de acumulação é aquele dominado pelas finanças.

${ }^{4}$ Segundo Boyer (2000), o regime de acumulação atual é "finance-led growth", pois a decisão de investimento não depende apenas do comportamento do consumo, como ocorria na era fordista, mas das restrições impostas pelo mercado de capitais. Nesse regime, um aumento da rentabilidade no mercado de capitais pode propiciar um ciclo virtuoso na economia, pois o consumo pode aumentar (efeito renda) e, se as empresas forem reativas a este aumento, o investimento pode se expandir.

5 Para Stockhammer (2004), o regime de acumulação atual é "finance-dominated growth" e não "finance-led growth". Segundo o autor, o aumento da rentabilidade das ações no mercado de capitais pode ter efeito ambíguo sobre o investimento e o consumo, não resultando necessariamente em um
} 
compra de ativos produtivos e imobilizados, resultando no crescimento mais lento das empresas e da economia.

Segundo Evans e Habbard (2008), a financeirização é um processo no qual os mercados e os serviços financeiros têm prioridade sobre a economia real. Para esses autores, a globalização e a liberalização financeira são conduzidas pelo capital financeiro, com efeitos sobre a distribuição de renda da economia, pois reduz a participação dos salários na renda total e favorece a ampliação da riqueza através das operações financeiras. A financeirização tornou-se a forma dominante de reprodução e acumulação da economia. Nesta mesma linha, Palley (2013) define a financeirização como a dominação da economia pelos interesses dos investidores financeiros, que impõem um modelo de governança voltado à criação de riqueza ao acionista, com impactos micro e macroeconômicos.

Para que as finanças se tornassem a forma dominante foi necessária uma ampla reforma institucional que subjugasse o processo de acumulação ao interesse do capital rentista $^{6}$ (Duménil e Lévy, 2001). Essa reforma foi conduzida pelos grandes investidores institucionais dos principais países desenvolvidos, pois são eles que determinam as regras do jogo no mundo globalizado (Chesnais, 2005). A ascensão do investidor institucional ${ }^{7}$ como o principal player do mercado financeiro conferiu ao acionista uma maior influência na determinação das estratégias das empresas e foi fator determinante nesse processo (Lazonick e O'Sullivan, 2000).

Como apontado por Crotty (2003), os investidores institucionais têm metas e comportamentos diferentes dos investidores individuais, pois são mais impacientes em relação ao retorno do capital e querem um maior grau de liquidez dos seus ativos e de diversificação do risco (ao contrário do investidor individual, que tende a ser mais paciente em relação ao retorno do capital e busca resultado de longo prazo). Esses objetivos moldam o comportamento dos investidores institucionais da seguinte forma: a) como desejam maior grau de liquidez de seus ativos, consideram os títulos de propriedade como ativos financeiros, exigindo um retorno compatível com a rentabilidade de mercado; b) dada sua impaciência em relação ao retorno do capital, se preocupam com resultados de curto prazo, consequentemente, pressionam o gestor por maior retorno financeiro e grandes distribuições de dividendos; c) para diversificar o risco, setorial e geográfico, não desejam o controle majoritário das organizações; d) não almejam participar diretamente da gestão das empresas, mas participam das decisões por meio do conselho de administração.

ciclo virtuoso. Dado que o gestor pode priorizar a distribuição de recursos líquidos da empresa ao acionista ao invés de investir em ativos produtivos, o crescimento da empresa e da economia pode ser prejudicado. Assim, o crescimento da economia, como descrito por Boyer (2000), nem sempre ocorrerá e, o regime "finance-led growth" é um caso especial do "finance-dominated growth".

${ }^{6}$ De acordo com Duménil e Lévy (2001), com objetivo de impor a dominância financeira e controlar qualquer força social que pudesse impedir o progresso das finanças, o neoliberalismo estabeleceu uma nova ordem social cujas características são: desemprego duradouro, com o objetivo de reduzir o poder dos sindicatos e controlar os custos do trabalho; imposição de uma nova governança corporativa voltada para os interesses dos acionistas; e uso da crise da dívida dos países em desenvolvimento nos anos de 1980 para impor a estes a lógica financeira e a redução das intervenções do Estado na economia.

7 De acordo com Crotty (2003), nos Estados Unidos da década de 1960 os investidores institucionais possuíam $12 \%$ das ações e as famílias $62 \%$. Porém, na década de 1990 , passam a deter $42 \%$ das ações e em 2005, 65\%. Além disso, em 2005 detinham 68\% das ações das 1000 maiores empresas norteamericanas. Portanto, observa-se o aumento da concentração do capital nos Estados Unidos nas mãos destes investidores e a redução do tempo médio na posse das ações, que passou de dez anos na década de 1980 para no máximo um ano na década de 1990. 
A mudança do perfil do investidor, de individual para institucional, provocou uma mudança na gestão das empresas não-financeiras de "reter e investir" para "downsizing e distribuir" (Lazonick e O'Sullivan, 2000). Assim, as empresas devem buscar as atividades mais rentáveis, de forma que plantas industriais sem rentabilidade compatível com o mercado devem ser vendidas e tarefas não diretamente relacionadas com a atividade fim da empresa devem ser terceirizadas. O objetivo é reorganizar o processo de produção de forma a aumentar a rentabilidade financeira e o retorno aos acionistas. A redução do tamanho da empresa atende aos interesses do mercado, pois empresas concentradas em conglomerados e estruturas piramidais dificultam o controle por parte dos acionistas externos e dos minoritários, elevando os custos de monitoramento (Plihon, 2005).

Práticas financeiras e patrimoniais passaram a ser utilizadas pelas empresas para aumentar o lucro por ação e o seu valor de mercado (Aglietta, 2000). As empresas ampliaram suas operações financeiras e a posse de ativos financeiros em seus balanços, não apenas como reserva de capital para investimentos futuros, mas como uma nova fonte de geração de riqueza presente e futura (Coutinho e Belluzzo, 2004), levando à importância crescente das receitas não operacionais para a empresa. Em casos mais extremos, a importância da renda financeira é tão significativa que a empresa, apesar de altamente endividada, apresenta resultados financeiros positivos substanciais. Estas práticas financeiras, conjugadas com 0 aumento da distribuição de riqueza ao acionista ${ }^{8}$, têm reduzido os recursos disponíveis para a compra de imobilizado, resultando no aumento do endividamento, da fragilidade financeira e no crescimento mais lento das empresas (Orhangazi, 2007; Stockhammer, 2004 e 2010 e Davis, 2013), além de prejudicar a inovação tecnológica das empresas não-financeiras (Lazonick, 2012).

Ao longo deste artigo adotamos a definição de financeirização como um novo regime de acumulação, onde as atividades produtivas são subordinadas ao capital financeiro. Acreditamos que este processo é caracterizado pelo aumento das atividades financeiras das empresas não-financeiras e pela governança corporativa voltada à criação de riqueza ao acionista.

\subsection{O Processo de Financeirização da Economia Brasileira}

O processo de financeirização nos países em desenvolvimento se diferencia dos países desenvolvidos. Isto se deve à heterogeneidade socioeconômica e à dependência de importações em setores importantes da economia ${ }^{9}$ dos países em desenvolvimento (BECKER et al, 2000). Os países adequam seu regime de acumulação às estruturas institucionais vigentes, de forma que os regimes de acumulação nos países em desenvolvimento assumem características distintas dos países centrais (Lipietz, 1984 e Bonizzi, 2014). Nada garante que os países irão convergir para um único regime de acumulação. Portanto, a convergência ao processo de financeirização pode ocorrer sem a necessidade da adoção completa dos preceitos ou das instituições neoliberais (Cioffi, 2010).

No Brasil, o desenvolvimento da financeirização assumiu um caráter específico, baseando-se na indexação dos títulos da dívida pública e no endividamento interno do setor público, sendo condicionado pela estrutura macro-institucional do país. Ao contrário das economias mais desenvolvidas - onde a financeirização decorreu principalmente do

\footnotetext{
${ }^{8}$ Segundo Evans e Habbard (2008), na maioria dos países da OCDE, o crescimento da distribuição dos dividendos tem sido maior que o crescimento dos lucros. Na década de 1990 a razão entre a variação dos dividendos e a variação dos lucros cresceu $51 \%$ nos Estados Unidos, 92\% na Itália, $88 \%$ na Suíça e $78 \%$ na França.

${ }^{9}$ Becker et al (2000), apresenta o conceito de Financeirização Periférica, para explicar esse processo nas economias em desenvolvimento.
} 
endividamento das famílias e empresas em um contexto de juros reduzidos - no Brasil, esse processo aconteceu em um ambiente de juros elevados e distribuição da riqueza em favor dos detentores da dívida pública interna (Bruno et al, 2011; Bonizzi, 2014).

Bruno e Caffé (2015) dividem a financeirização da economia brasileira em dois períodos. O primeiro abrange os anos de 1970 a 1993, caracterizados pela aceleração da inflação, desequilíbrio das contas públicas, mecanismos de correção monetária e um ambiente econômico de elevada incerteza. O segundo período se inicia em 1994 e se estende até os tempos atuais, sendo marcado pela estabilização dos preços e a manutenção de elevadas taxas de juros nominais e reais. O processo de financeirização do país teria começado na década de 1970, com a aceleração da inflação e a indexação, impondo uma lógica financeira ou patrimonialista. Nos anos 1980, o aumento do endividamento do setor público e os fracassos dos planos de estabilização afetaram negativamente as expectativas em relação à capacidade do Estado de gerenciar as políticas monetária e fiscal. Os agentes privados, temendo a redução do valor do seu patrimônio, pressionaram o Estado para manter inalterada sua riqueza por meio do aumento da transferência de renda através do capital rentista (Cano, 1999; Belluzzo e Almeida, 2002). Bruno et al (2011) definem o padrão de financeirização neste período como inflacionista.

O retorno dos títulos públicos, principalmente na década de 1980, tornou-se o balizador do retorno dos investimentos produtivos, o que, conjugado ao ambiente econômico de elevada incerteza, levou as empresas não-financeiras a adotar uma estrutura patrimonial mais defensiva, afetando suas políticas de financiamento, de investimento e de formação de preços (Frenkel e Fanelli, 1995). Para se proteger da desvalorização patrimonial, as empresas mudaram o foco para resultados de curtíssimo prazo, elevando o markup, reduzindo o endividamento (o que diminuiu as despesas financeiras), aumentando a velocidade de rotação dos estoques e reduzindo o investimento produtivo. Essas medidas possibilitaram o aumento da geração de recursos próprios internos e da taxa de retenção. A elevação da taxa de retenção e a redução do investimento levaram as empresas a deslocar parte dos recursos líquidos disponíveis para aplicações mais rentáveis, principalmente, ativos financeiros indexados (Pereira, 2000; Belluzzo e Almeida, 2002).

Com a estabilização da economia e o fim da correção monetária em 1994, os ganhos inflacionários diminuíram. Porém, o aprofundamento das reformas neoliberais, durante todo o período, e a manutenção de elevadas taxas reais de juros permitiram o avanço do processo de financeirização e do ganho financeiro com os juros (Bruno E Caffé, 2015). A estabilização dos preços foi marcada por uma gama de reformas institucionais, micro e macroeconômicas. Seguindo os preceitos neoliberais, essas reformas foram guiadas pela liberalização e desregulamentação da conta capital e financeira do balanço de pagamentos, do setor bancário e do mercado de capitais. Essas mudanças institucionais levaram ao desenvolvimento de novos produtos financeiros e ao surgimento de novos atores, principalmente dos investidores institucionais estrangeiros no mercado de capitais brasileiro (Prates, 1997; Carneiro, 2002).

O novo marco regulatório, resultado das reformas liberalizantes, permitiu que as empresas não-financeiras ampliassem suas fontes de financiamento. Além de captar recursos via endividamento junto ao setor bancário externo e via emissão de títulos de renda fixa no exterior, estas empresas passaram a emitir títulos de renda variável no mercado de capitais internacional (Prates, 1997; Carneiro, 2002). Estes títulos, denominados recibos de depósitos (Depositary Receipts - DRs), são negociados no mercado nacional e podem ser renegociados ou mantidos em custódia no mercado norte-americano (American Depositary Receits - ADRs) ou em outros mercados internacionais (Global Depositary Receipts - GDRs). Além destes, devido ao aumento da concorrência nos mercados de capitais internacionais e à necessidade de ampliar o mercado de capitais nacional, em 1996, foram criados os Brazilian Depositary 
Receipts (BDRs), os quais permitem que empresas estrangeiras negociem suas ações no mercado doméstico, levando à internacionalização do mercado de capitais brasileiro.

A partir do ano 2000, ocorre o aprofundamento do processo de financeirização da economia brasileira (Bruno e Caffé, 2015) como resultado do aumento da taxa de juros real e nominal em 1998, do aumento do endividamento interno do setor público e das reformas liberalizantes. Neste contexto, as empresas não-financeiras modificaram seu padrão de financiamento de longo prazo, como se pode ver nos trabalhos de Singh (1995), Zonenschain (1998), Moreira e Puga (2001) e Filleti (2010). Até então, a principal fonte era a emissão de ações, seguida do endividamento e, por último, recursos próprios internos. A partir do final da década de 1990, o autofinanciamento se tornou a principal fonte de recursos e houve o aumento do uso de dívidas. As empresas aumentaram a recompra de ações, o que reduziu a participação desta fonte no financiamento (Filleti, 2010). Estas alterações caracterizam um aprofundamento da financeirização da economia brasileira, pois, segundo Plihon (2005), o uso de fundos próprios e a redução de emissão de ações são características do processo de financeirização.

Além disto, houve também um crescimento da distribuição de riqueza ao acionista, na forma de dividendos e juros sobre o capital próprio, e da rentabilidade do capital, mostrando um direcionamento da governança para a criação de riqueza ao acionista, com impactos negativos sobre a geração de emprego (Attílio, 2016). Essa mudança no padrão de financiamento juntamente com o aumento das atividades financeiras das empresas e da distribuição de riqueza ao acionista diminuíram a taxa de retenção e os recursos disponíveis para a compra de imobilizado, resultando na queda da taxa de investimento e no aumento da fragilidade das empresas (Corrêa et al, 2017).

\section{Estrutura de Controle e Investimento Produtivo das Empresas Não-Financeiras}

A origem da discussão sobre governança corporativa remonta às contribuições de Berle e Means (1932) e de Jensen e Meckling (1976) sobre a separação entre propriedade e controle e sobre a dispersão da propriedade do capital. A partir desses trabalhos seminais desenvolveuse uma literatura em torno dos problemas de agência. A dispersão do capital implica que os acionistas se tornam agentes passivos na tomada de decisão. Ao contrário do que ocorre em empresas de propriedade familiar ou com estrutura de capital concentrada, nas quais os acionistas controlam os bens produtivos e são responsáveis por eles, no capitalismo disperso, os acionistas possuem um pedaço de papel representando direitos e expectativas, tendo pouco controle sobre os meios de produção. As decisões sobre a empresa e sobre a maximização de sua riqueza são tomadas pelos agentes. Portanto, a separação entre o controle e a propriedade dá origem ao conflito entre o acionista e o gestor (Berle E Means, 1932).

Apesar da importância do mercado de capitais e da aderência crescente ao princípio do "maximization of shareholder value", em vários países ainda há muitas empresas com altos níveis de governança corporativa em que o capital é concentrado nas mãos de acionistas controladores, possuindo baixa dispersão (La Porta et al, 1999 e Singh, Singh e Weisse, 2002). Nesta situação existe o risco de expropriação da riqueza dos acionistas minoritários por parte do acionista controlador através de estruturas piramidais, propriedade cruzada de ações intercompanhias, duas classes de ações e acordos de acionistas em que há transferência de recursos para os controladores, além de afastarem o acionista de seu direito a "uma ação um voto" (Shleifer E Vishny, 1996; Maher e Andersson, 1999; Krueger, 2002). Essas estratégias permitem ao grande acionista controlar a empresa sem a necessidade de ter a maioria do seu capital. 
A estrutura piramidal permite ao controlador expropriar a riqueza do minoritário através de transferências internas de recursos, financeiros e reais, entre as empresas do grupo (tunneling) para o benefício do controlador (Johnson et al, 2000). Ao dificultar e elevar os custos de monitoramento, esta estrutura possibilita ao acionista principal extrair benefícios privados da firma que controla às custas dos minoritários (Wolfenzon, 1999; Almeida e Wolfenzon, 2006).

Por outro lado, as estruturas piramidais facilitam o negative tunneling, permitindo transferências de recursos entre empresas ou dos acionistas controladores para empresas em dificuldades, minimizando os efeitos para os acionistas minoritários (Friedmann et al, 2003). Além disto, essas estruturas podem contribuir para facilitar o fluxo de informações entre empresas em mercados caracterizados por informação incompleta através de relacionamentos formais e informais. A coordenação ex ante de planos de investimento e de transações também é importante (Richardson, 1972), possibilitando a redução dos riscos e dos custos de transação (Williamson, 1985; Flath, 1992; Kesler, 1992). A estrutura piramidal possibilita a mobilização de poupança interna (um corporate treasure) que poderia atuar como um surrogate ou de facto corporate venture capital, provendo recursos para a criação de novas empresas, ou ainda atuando na estabilização do desempenho das empresas existentes, evitando cenários muito ruins (Gerlach, 1992; Akyuz e Gore, 1996).

Não cabe aqui realizar uma discussão exaustiva sobre os argumentos da expropriação, mas cumpre destacar que esta visão se fortaleceu ao longo dos anos à medida que a financeirização passou a fazer parte não só da forma de operação das empresas não financeiras, mas também das famílias. Isso significa que muitas empresas viram a oportunidade de se beneficiarem da rápida expansão do mercado de capitais, bastando participar do "jogo". O crescimento do mercado de capitais em escala global só poderia ser sustentado se o mercado ganhasse liquidez nos países emergentes. Para isso era necessário alterar o controle do capital das empresas em direção ao controle disperso e impor regras comuns para as demonstrações financeiras e para sua organização interna. Isso implicou no movimento dos mercados emergentes em direção ao golden standard do modelo anglo-saxão (CHANG, 2005). As instituições internacionais, como a Organização para a Cooperação e Desenvolvimento Econômico (OCDE), Fundo Monetário Internacional (FMI) e Banco Mundial, passaram a apresentar estudos destacando as consequências negativas do capitalismo "oligárquico", baseado em controle concentrado da propriedade sobre as taxas de crescimento, o grau de inovação, etc.

A governança corporativa (GC) pode ser entendida como um conjunto de regras internacionalmente reconhecidas de controles internos e externos às empresas para garantir maior transparência, minimizar os riscos de perdas e maximizar o retorno para os acionistas/investidores. Internamente às empresas, a GC trata das relações entre a direção da empresa, o conselho de administração, os acionistas e demais stakeholders (OCDE, 2004). Ela deve ser capaz de promover a eficiência corporativa (entendida como maximização do lucro para o acionista) e ainda controlar os riscos a que as empresas estão sujeitas nas suas operações financeiras e não-financeiras (Shleifer e Vishny, 1996). Externamente às empresas, a GC é constituída por uma série de instituições que visam a minimização de riscos para os acionistas/investidores por meio da verificação e certificação da integridade e veracidade das demonstrações financeiras apresentadas de forma a evitar perturbações (significativas) nos mercados. Estas instituições são denominadas gatekeepers (vigias de mercado), e incluem auditores independentes, analistas de mercado, agências de risco, advogados e instituições de 
"vigia" das operações das bolsas (como a CVM ou SEC), que são responsáveis pela verificação e certificação das informações divulgadas pelas empresas ${ }^{10}$.

Para disseminar o golden standard anglo-saxão, a OCDE, por exemplo, possui guias de boas práticas de GC nos quais sugere várias condutas às empresas, tais como: melhorar a transparência, adotar um padrão de contabilidade confiável e aceito internacionalmente, promover equidade de tratamento entre os acionistas, permitir auditorias independentes quando necessário, promover eleições de membros do conselho de administração independente, manter um mínimo de ações em circulação nos mercados de capitais e a política de 'uma ação-um voto'.

\subsection{Trabalhos Empíricos sobre Estrutura de Propriedade no Mundo e no Brasil}

Os trabalhos empíricos têm mostrado que o capital tende a ser menos concentrado nos países anglo-saxões e no Japão e mais concentrado nos países europeus continentais e latino-americanos. Segundo Demsetz e Lehn (1985), de uma amostra das 511 maiores empresas norte-americanas, em apenas $6,65 \%$ o capital era majoritário (tinha a presença de um acionista controlador) e os cinco principais acionistas detinham, em média, 24,81\% do capital total. Para a economia japonesa, Prowse (1992) mostrou que os cinco principais acionistas detinham, na média, 33,1\% do capital total. Weib (2010) observou que os cinco principais acionistas detinham, em média, $24,71 \%$ do capital total na economia norteamericana; $24,71 \%$ na economia inglesa e $32,47 \%$ na economia japonesa.

A partir de uma mostra de 540 empresas de capital aberto de 27 países La Porta et al (1999) mostraram que em apenas 33,33\% destas empresas o capital era disperso e que quase $30 \%$ eram controladas pelas famílias e $18 \%$ pelo Estado ${ }^{11}$. Em relação aos países, o capital era disperso em $100 \%$ das empresas do Reino Unido que faziam parte da amostra; em $90 \%$ das empresas do Japão; e em $88 \%$ das empresas dos Estados Unidos. Já na Argentina não se observou dispersão de capital para nenhuma das empresas constantes da amostra e na Áustria, Bélgica e Israel em apenas $5 \%$ das empresas o capital era disperso.

Crespi-Cladera e Garcia-Cestora (1999) mostraram que na Espanha os três principais acionistas detinham, em média, 47,1\% do capital total das empresas. Segundo Cueto (2013), os três principais acionistas detinham $65,50 \%$ das ações com direito a voto na América-Latina, e no Brasil os acionistas detinham, em média, $55,76 \%$ do capital votante.

Siqueira (1998), utilizando a metodologia de Demsetz e Lehn (1985), para uma amostra de 278 empresas brasileiras de capital aberto, observou que em $21,22 \%$ destas o capital total era disperso; em $48,20 \%$ o capital total era dominante e em $30,58 \%$ era majoritário. Mas, ao considerar as ações com direito a voto, o capital tende a ser mais concentrado, pois somente em $7,51 \%$ das empresas o capital era disperso, em $24,82 \%$ o capital era dominante e, em $67,63 \%$ era majoritário (tabela 1 ).

Usando uma amostra de 602 empresas de capital aberto da BM\&FBovespa no ano de 2001, Aldrighi e Mazzer Neto (2005) mostraram que o principal acionista detinha, em média, $52,4 \%$ do capital que dá direito ao fluxo de caixa e $76,94 \%$ do capital votante. Além disto, o capital era majoritário em $83,38 \%$ das empresas e o esquema de pirâmide ocorreu em $68,11 \%$ das empresas da amostra (tabela 1).

\footnotetext{
${ }^{10}$ Ver a este respeito a Lei Sarbanes-Oxley (2002) promulgada após o escândalo da Enron.

11 La Porta et al (1999) realizaram um trabalho empírico para determinar a estrutura de propriedade e controle das 27 economias mais ricas do mundo, observando as 20 maiores empresas de capital aberto e as ações com direito a voto.
} 
Aldrighi e Mazzer Neto (2007) realizaram um estudo para as empresas brasileiras de capital aberto no período de 1997-2002. O principal acionista detinha, em média, 72,9\% do capital votante e $51,6 \%$ do capital com direito ao fluxo de caixa, e $77,6 \%$ das empresas apresentavam um acionista controlador para a média do período. Neste período, houve uma redução da participação das famílias como principal acionista, passando de $58,2 \%$ das empresas em 1997 para $54,7 \%$ em 2002, e do governo de $9 \%$ para $7,5 \%$. Por outro lado, houve o aumento da participação de estrangeiros de $14,5 \%$ para $18,5 \%$ e dos investidores institucionais de $1,9 \%$ para $5,2 \%$, no mesmo período (tabela 1 ).

Tabela 1. Concentração do Capital Votante em Siqueira (1998) e Aldrighi e Mazzer Neto (2005 e 2007)

\begin{tabular}{|c|c|c|}
\hline Autor & Concentração do capital & Frequência Relativa \\
\hline \multirow{3}{*}{ Siqueira (1998) } & Disperso: até $20 \%$ & $7,51 \%$ \\
\hline & Dominante: de $20 \%$ a $50 \%$ & $24,82 \%$ \\
\hline & Majoritário: mais de $50 \%$ & $67,63 \%$ \\
\hline \multirow{4}{*}{$\begin{array}{l}\text { Aldrighi e Mazzer Neto } \\
\text { (2005) }\end{array}$} & Até $10 \%$, inclusive & $0,17 \%$ \\
\hline & De $10 \%$ a $20 \%$, inclusive & $4,32 \%$ \\
\hline & De $20 \%$ a $50 \%$, inclusive & $12,3 \%$ \\
\hline & Mais de $50 \%$ & 83,29 \\
\hline \multirow{4}{*}{$\begin{array}{l}\text { Aldrighi e Mazzer Neto } \\
\qquad(2007)^{*}\end{array}$} & Até $10 \%$, inclusive & $0,4 \%$ \\
\hline & De $10 \%$ a $25 \%$, inclusive & $5,6 \%$ \\
\hline & De $25 \%$ a $50 \%$, inclusive & $16,4 \%$ \\
\hline & Mais de $50 \%$ & $77,6 \%$ \\
\hline
\end{tabular}

*Média para o período de 1997-2002.

Fonte: Elaboração própria a partir de Siqueira (1998), Aldrighi e Mazzer Neto (2005 e 2007).

Gorga (2009) realizou um trabalho empírico para uma amostra de 339 empresas nãofinanceiras de capital aberto, observando o primeiro acionista, os três e os cinco principais acionistas e dividiu as empresas de acordo com o seu segmento de mercado da BM\&FBovespa (mercado tradicional, Nível 1 e 2 e Novo Mercado) para o ano de 2006. A autora concluiu que: as famílias e os indivíduos são os principais acionistas das empresas não-financeiras da BM\&FBovespa; houve um aumento da participação do investidor institucional como o principal acionista; as empresas que fazem parte do NM tendem a ter capital mais disperso e menor presença do acionista controlador; a estrutura piramidal ocorre em 19,54\% das empresas do NM e em $38,79 \%$ das empresas do mercado tradicional. Os principais resultados encontram-se na tabela 2. 
Tabela 2: Concentração do capital votante, perfil dos acionistas e presença de acionistas majoritários para as empresas do NM, N2, N1 e Tradicional segundo Gorga (2009)

\begin{tabular}{c|c|c|c|c|c}
\hline \multirow{4}{*}{$\begin{array}{c}\text { Concentração do } \\
\text { capital votante }\end{array}$} & Segmento BM\&FBovespa & NM & N2 & N1 & Tradicional \\
\cline { 2 - 5 } & Prês Primeiro Acionista & $36,39 \%$ & $64,79 \%$ & $63,14 \%$ & $65,80 \%$ \\
\cline { 2 - 6 } & Família e Indivíduos & $39,75 \%$ & $65 \%$ & $68,18 \%$ & $62,84 \%$ \\
\hline \multirow{2}{*}{$\begin{array}{c}\text { Perfil do principal } \\
\text { acionista }\end{array}$} & Estrangeiro & $21,86 \%$ & $25 \%$ & $9,09 \%$ & $20,22 \%$ \\
\cline { 2 - 6 } & Investidor Institucional & $15,08 \%$ & $0 \%$ & $13,64 \%$ & $7,10 \%$ \\
\cline { 2 - 6 } & Governo & $23,21 \%$ & $10 \%$ & $9,09 \%$ & $9,84 \%$ \\
\hline \multirow{2}{*}{$\begin{array}{c}\text { Acionista } \\
\text { majoritário }\end{array}$} & Presença & $29,34 \%$ & $70 \%$ & $70,45 \%$ & $83,06 \%$ \\
\cline { 2 - 6 } & Ausência & $70,65 \%$ & $30 \%$ & $29,54 \%$ & $16,93 \%$ \\
\hline
\end{tabular}

Fonte: Elaboração própria a partir dos dados da Gorga (2009).

Do exposto acima pode-se depreender que a dispersão de propriedade é exceção e não regra na economia mundial. No caso do Brasil, os trabalhos têm evidenciado uma mudança na concentração do controle das empresas não financeiras, principalmente nas empresas do NM. Na próxima seção apresenta-se uma análise empírica que identifica a estrutura de controle das empresas não-financeiras do NM da Bovespa.

\section{Estrutura de Controle das Empresas Não-Financeiras do NM}

Para identificar a estrutura de controle das empresas não-financeiras no mais alto nível de governança da BM\&FBovespa, foram observados o principal acionista ${ }^{12}$ (P1) e os três principais acionistas (P3). As informações foram obtidas nos relatórios enviados à Comissão de Valores Mobiliários (CVM), nos relatórios contábeis e nas notas explicativas, os quais estão disponíveis no site da BM\&FBovespa. Foram observadas 118 empresas não-financeiras do NM no ano de 2012 , correspondendo a $93,54 \%$ das empresas deste seguimento ${ }^{13}$. Consideraram-se apenas os acionistas que possuíam, direta ou indiretamente, ações com direito a voto e que constavam na estrutura acionária disponível na BM\&FBovespa e $\mathrm{CVM}^{14}$.

No caso de uma estrutura de controle indireto, a estrutura acionária foi aberta para trás até encontrar o maior último acionista, verificando se ele é controlador ${ }^{15}$ ou não da empresa. Se ele não for o controlador, o cálculo foi feito da seguinte forma: suponha que um acionista detenha $35 \%$ das ações da empresa A, a qual controla $40 \%$ das ações da empresa B.

\footnotetext{
12 Nos casos em que os principais acionistas são membros de uma ou mais famílias, considerou-se a família como o principal acionista, com participação igual à soma das parcelas de seus membros, seja esta direta ou indireta.

${ }^{13}$ As empresas do NM corresponderam a quase 31\% da capitalização, 30\% das empresas de capital aberto e 44\% das transações na BM\&FBovespa no ano de 2012.

${ }^{14}$ As empresas do NM só podem emitir ações com direito a voto.

${ }^{15} \mathrm{O}$ acionista controlador, neste caso, é aquele que possui, ao longo da cadeia de empresas, mais de $50 \%$ do capital votante de cada uma das empresas.
} 
Então, este acionista detém $14 \%$ das ações da empresa $B(0,35 \times 0,40=0,14)$. Se o principal último acionista for o controlador, o total das ações com direito a voto é determinado pela quantidade de ações com direito a voto que a última empresa intermediária possui da empresa de interesse.

A classificação da concentração da propriedade baseou-se na metodologia de Thomsen e Pedersen (1997) em que o controle da empresa é considerado: 1) Disperso: se o principal acionista detém menos que $20 \%$ do capital votante; 2) Dominante: se o principal acionista detém entre $20 \%$ e $50 \%$ do capital votante, e 3) Majoritário: se o principal acionista tem mais de $50 \%$ do capital votante.

Utilizando a metodologia proposta pelo IBGC (2009), o principal controlador das empresas foi classificado da seguinte maneira: 1) Família; 2) Indivíduo; 3) Investidores Institucionais, os quais são subclassificados em: 3.1) Fundos de Pensão, 3.2) Fundos de Investimento, 3.3) Bancos e 3.4) Outros (cooperativas, seguradoras); 4) Estado: quando o principal acionista é o governo Federal, Estadual ou Municipal e 5) Estrangeiro: sejam famílias, indivíduos, empresas, bancos ou investidores institucionais (fundos de pensão, bancos ou fundos de investimento).

\subsection{Estudo do Controle de Propriedade das Empresas do NM}

Considerando-se o primeiro acionista (P1) nas empresas do NM, observou-se que o capital é disperso em $26,27 \%$ das empresas, dominante em $38,98 \%$ e majoritário em $34,37 \%$ (tabela 3 ). $\mathrm{Na}$ maioria das empresas (quase $65 \%$ ) não há a presença de um acionista majoritário. Ao considerar os três principais acionistas (P3), observou-se que o capital tende a se tornar mais concentrado: apenas em 3,38\% das empresas o capital é disperso, sendo que em $34,75 \%$ o capital é dominante e em $61,68 \%$ o capital é majoritário.

Tabela 3: Estrutura de Controle das Empresas do Novo Mercado da GC da BM\&FBovespa para o Principal Acionista (P1) e até Três Acionistas (P3)

\begin{tabular}{c|c|c|c|c}
\hline & \multicolumn{2}{|c|}{ Principal Acionista (P1) } & \multicolumn{2}{c}{ Até 3 Acionistas (P3) } \\
\hline Concentração de Propriedade & $\begin{array}{c}\text { Frequência } \\
\text { Absoluta }\end{array}$ & $\begin{array}{c}\text { Frequência } \\
\text { Relativa }\end{array}$ & $\begin{array}{c}\text { Frequência } \\
\text { Absoluta }\end{array}$ & $\begin{array}{c}\text { Frequência } \\
\text { Relativa }\end{array}$ \\
\hline Disperso & 31 & $26,27 \%$ & 4 & $3,38 \%$ \\
\hline Dominante & 46 & $38,98 \%$ & 41 & $34,75 \%$ \\
\hline Majoritário & 41 & $34,75 \%$ & 73 & $61,86 \%$ \\
\hline Total & 118 & $100 \%$ & 118 & $100 \%$ \\
\hline
\end{tabular}

Fonte: Elaboração própria a partir dos dados disponíveis na CVM e BM\&FBovespa.

Como nos trabalhos apresentados anteriormente, considerando-se o P1, a Família é o principal acionista em $34,75 \%$ das empresas do NM, seguida pelo Indivíduo, principal acionista em 23,75\% destas empresas. Em seguida estão os Estrangeiros em 16,95\%, Bancos em 9,32\%, private equities em $7,63 \%$, fundos de pensão e Estatal em 3,39\%, cada, e outros investidores institucionais em $0,85 \%$ das empresas (tabela 4 ). 
Tabela 4: Característica do Principal Acionista (P1) das Empresas do Novo Mercado da BM\&FBovespa

\begin{tabular}{|c|c|c|c|}
\hline \multicolumn{2}{|c|}{ Característica do Acionista } & Frequência & Frequência \\
\hline \multicolumn{2}{|c|}{ Família } & 41 & $34,75 \%$ \\
\hline \multicolumn{2}{|c|}{ Indivíduo } & 28 & $23,75 \%$ \\
\hline \multirow{4}{*}{$\begin{array}{l}\text { Investidor } \\
\text { Institucional }\end{array}$} & Fundos de Pensão & 4 & $3,39 \%$ \\
\hline & Private Equity & 9 & $7,63 \%$ \\
\hline & Bancos & 11 & $9,32 \%$ \\
\hline & Cooperativas & 1 & $0,85 \%$ \\
\hline \multicolumn{2}{|c|}{ Estatal } & 4 & $3,39 \%$ \\
\hline \multicolumn{2}{|c|}{ Estrangeiro } & 20 & $16,95 \%$ \\
\hline \multicolumn{2}{|c|}{ Total } & 118 & $100 \%$ \\
\hline
\end{tabular}

Fonte: Elaboração Própria através dos dados disponíveis na CVM e BM\&FBovespa.

Em relação à propriedade, alguns pontos merecem destaque. $O$ primeiro refere-se ao controle exercido pelos bancos, onde 6 bancos privados e 5 estatais detém, em média, $37 \%$ do capital votante. Entre os bancos estatais, o Banco do Brasil é o principal acionista de uma empresa e o BNDES de 4 empresas. Mas, quando se considera os três principais acionistas, o BNDES é acionista em 11 empresas da amostra (9,32\% do NM), mostrando uma participação significativa desse banco estatal no financiamento das empresas do NM. Esta participação pode estar relacionada ao objetivo do banco em desenvolver o mercado de capitais e aumentar a transparência da gestão das empresas em que o banco é acionista. Para isto, o banco tem direcionado as empresas a abrir o capital nos níveis de governança mais elevados (Coutinho e Rabelo, 2003).

O segundo ponto a ser destacado é a participação dos investidores estrangeiros. Em média, esses acionistas detêm $37,5 \%$ do capital votante. Desses investidores, $40 \%$ são Private Equity, $45 \%$ são empresas estrangeiras e $15 \%$ são indivíduos ou famílias estrangeiras. 0 aumento desses investidores estrangeiros é resultado da ampliação do processo de liberalização e desregulamentação do mercado de capitais nacional que ocorreu nos governos FHC e Lula.

O terceiro destaque é o aumento substancial da presença dos investidores institucionais na posição de principal acionista das empresas do NM. Esses investidores detinham 6,52\% das empresas do NM (6 empresas) no ano de 2006 (Gorga, 2009), aumentando para 21,19\% (25 empresas) em 2012. Uma característica importante do processo de financeirização é o aumento do Private Equity como principal acionista ou um dos principais acionistas. Os Private Equity controlam 7,63\% das empresas do NM e detém, em média, 36,9\% do capital votante. Considerando-se os Private Equity nacionais e estrangeiros, observa-se que este tipo de investidor institucional é o principal acionista em $14,41 \%$ das empresas da amostra. Mas observando os três principais acionistas (P3), a participação desses investidores aumenta para quase $50 \%$ das empresas da amostra. Um exemplo de atuação deste tipo de acionista é o grupo GP do Brasil, um Private Equity que é o principal acionista em 6 (seis) 
empresas de diferentes setores da economia: educação, comércio varejista, hotelaria, exploração de imóveis (shopping centers), saúde e indústria (metalurgia). A composição da carteira com empresas de diferentes ramos da atividade econômica permite menor correlação entre os ativos, minimizando o risco do portfólio, assim como faz o investidor individual.

No NM, o principal acionista (P1) detém, em média, 38,45\% do capital votante e os três principais acionistas (P3) detêm, em média, 52,66\% deste capital. As empresas do NM tendem a possuir maior concentração de capital do que as congêneres norte-americanas e inglesas. Mas o capital deste seguimento tende a ser mais disperso e o controle menos concentrado do que nos outros segmentos da BM\&FBovespa ou do que a média das empresas latino-americanas (tabela 5). Isto significa que o capital está ficando menos concentrado para as empresas que participam do nível mais alto de governança da BM\&FBovespa, quando comparado com os trabalhos anteriores apresentados, mas ainda é mais concentrado que a média dos países anglo-saxões.

Tabela 5: Controle das Ações com Direito a Voto para o Primeiro (P1) e os Três Maiores (P3) Acionistas das Empresas do Novo Mercado da BM\&FBovespa, das Empresas Norte-Americanas e das Empresas da América Latina

\begin{tabular}{c|c|c|c|c}
\hline \multicolumn{2}{c|}{} & Média & Maior Valor & Menor Valor \\
\hline NM & P1 & $38,45 \%$ & $88,30 \%$ & $0,07 \%$ \\
\cline { 2 - 5 } & P3 & $52,66 \%$ & - & - \\
\hline NM (Gorga, 2009)* & $52,28 \%$ & n.d. & n.d. \\
\hline Empresas latino-americanas (Cueto, 2013)* & $65,50 \%$ & n.d. & n.d \\
\hline Empresas norte-americanas (Weib, 2010)** & $24,75 \%$ & $72,17 \%$ & $0,94 \%$ \\
\hline
\end{tabular}

*Para os três principais acionistas. **Para os cinco principais acionistas.

Fonte: Elaboração própria através dos dados disponíveis na CVM e BM\&FBovespa.

A estrutura piramidal foi observada em $17,80 \%$ das empresas do NM. Gorga (2009) identificou esta estrutura em $19,54 \%$ das empresas do NM e em $38,79 \%$ das empresas do mercado tradicional. Pode-se inferir, então, que houve uma ligeira redução deste tipo de estrutura no NM, e que ela é mais presente nos demais segmentos da BM\&FBovespa, o que pode ser resultado da adoção de melhores práticas de governança.

Embora o capital seja mais concentrado no Brasil, as empresas do NM adotam outros mecanismos de governança para minimizar os efeitos desta concentração, como será mostrado a seguir. As boas práticas de governança impõem que as empresas disponibilizem apenas ações com direito a voto - 'uma ação-um voto' - permitindo maior participação dos acionistas minoritários nas decisões das empresas por meio da escolha dos membros do conselho de administração. Isto implica maior participação dos acionistas minoritários, podendo reduzir os riscos de expropriação e do tunneling.

\subsection{Ações com Direito a Voto e Free Float}

Seguindo as boas práticas de governança da OCDE, as empresas que fazem parte do NM só podem emitir ações ordinárias (uma ação-um voto). Além disto, as empresas da amostra mantêm, em média, 37,78\% das ações em free float - valor superior ao determinado pelas normas das boas práticas de GC da BM\&FBovespa, que é de pelo menos $25 \%$. Observouse que $21,3 \%$ das empresas mantêm mais da metade de suas ações em free float e $15,75 \%$ das 
empresas mantêm entre $40 \%$ e $50 \%$ nessa situação (gráfico 1). A maior parte das empresas $(56,47 \%)$ mantém entre $20 \%$ e $40 \%$ das ações em circulação. A empresa Gafisa S.A. é a que mais mantém ações em circulação $(99,54 \%)$ enquanto a empresa Port é a que possui menor percentual $(0,71 \%)$.

Gráfico 1: Percentual de Ações em Free-Float Empresas no Novo Mercado, 2012

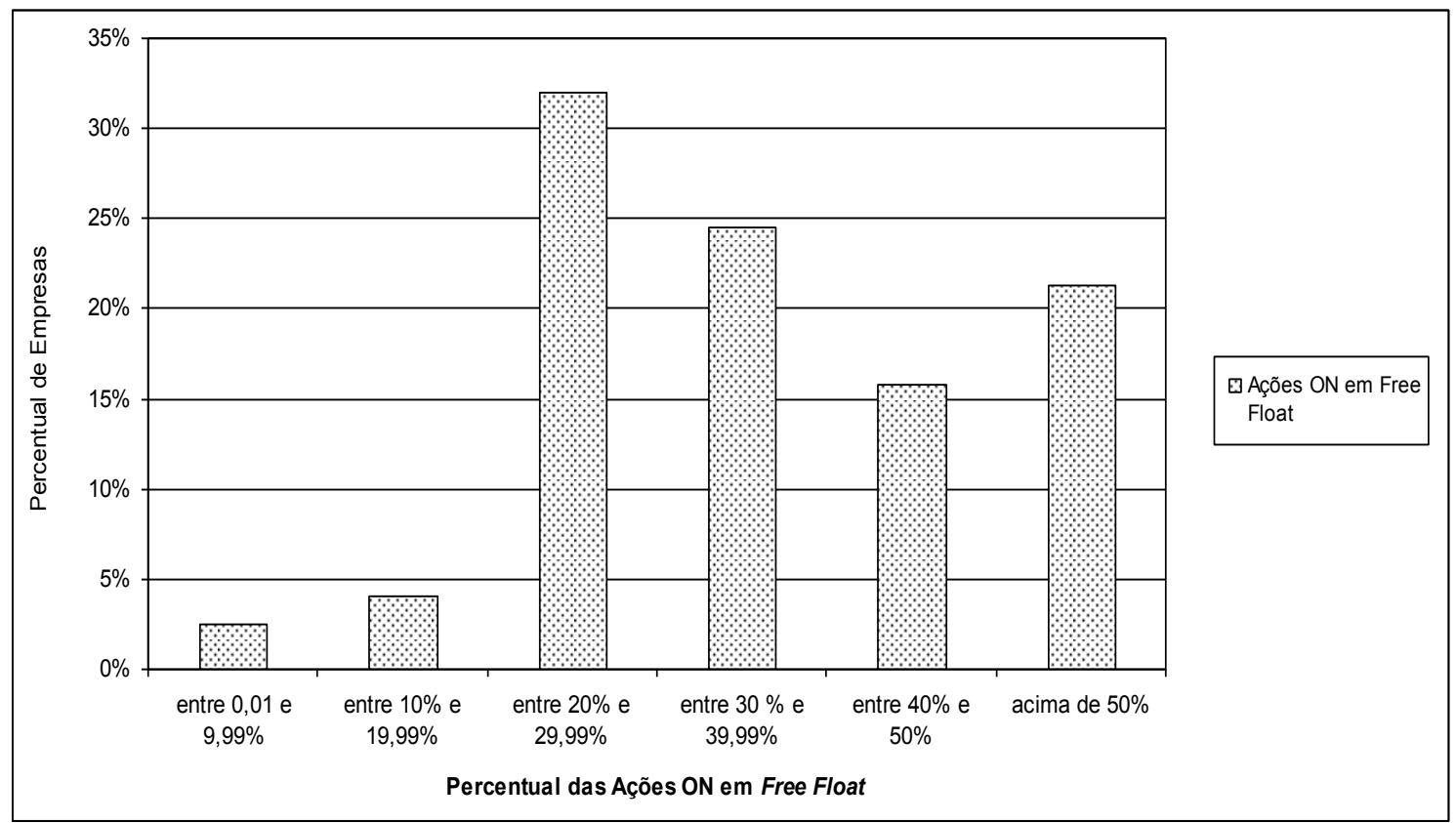

Fonte: Elaboração própria através dos dados disponíveis na BM\&FBovespa.

Assim, a emissão de um único tipo de ação das empresas do NM reduziu a presença do acionista majoritário, como pode ser observado nos trabalhos apresentados no tópico anterior. Este fato juntamente com as normas rígidas em relação à circulação das ações podem ser alguns dos fatores que resultaram em uma maior dispersão do capital e do controle, quando comparado com outros segmentos da BM\&FBovespa.

\section{Conclusão}

A estrutura de propriedade e controle determina a governança das empresas e os conflitos de agência. Porém, a literatura dominante sobre boas práticas de governança corporativa estabelece que a dispersão do capital aumenta a eficiência do controle do mercado sobre as empresas, forçando o alinhamento entre os interesses do gestor e do acionista (movimento de maximização da riqueza do acionista), sendo esta governança uma "first best solution".

A adoção de boas práticas de GC no NM resultou em uma estrutura de propriedade mais dispersa em relação aos outros segmentos de mercado da BM\&FBovespa, como pode ser visto no trabalho de Gorga (2009). Vale destacar que na maioria das empresas da amostra deste segmento não há um acionista majoritário, fato este pouco observado nos outros seguimentos da Bovespa. Também é significativo o aumento da presença de investidores institucionais, o que pode indicar o aprofundamento do processo de financeirização da economia brasileira.

O capital no NM ainda é mais concentrado do que nas economias anglo-saxãs. Porém, algumas práticas de governança corporativa das empresas deste seguimento estão alinhadas com o movimento de governança voltado à maximização da riqueza dos acionistas, tais como: tag along de 100\% para as empresas do NM, tamanho e formação do conselho de administração próximos ao que é considerado uma boa prática de governança pela OCDE, e 
informações contábeis disponíveis de forma padronizada e auditadas por agentes independentes.

Cabe salientar que esta convergência pode não ser completa devido às diferenças entre a estrutura macroinstitucional da economia brasileira e a dos países desenvolvidos, a qual afeta as decisões das empresas. Entretanto, as evidências encontradas sugerem que a financeirização afetou a estrutura de controle e o perfil dos acionistas, ampliando a dispersão do capital e aumentando a presença dos investidores institucionais e estrangeiros.

\section{Referências Bibliográficas}

Aglietta, M. (2000), "Shareholder Value and Corporate Governance: some tricky questions." Economy and Society, 29(1), p.146-159.

Akyuz, Y e Gore, C. (1996), "Profits Nexus in East Asian Industrialization." World Development, 24(3), p.461-470.

Aldrighi, D. M. e Mazzer Neto, R. (2005), "Estrutura de Propriedade e Controle das Empresas de Capital Aberto no Brasil." Revista de Economia Política, 25, p.115-137.

Aldrighi, D. M. e Mazzer Neto, R. (2007), "Evidências sobre as Estruturas de Propriedade de Capital e de Votos das Empresas de Capital Aberto no Brasil." Revista Brasileira de Economia, 61, p.129-152.

Almeida, H. V. e Wolfenzon, D. (2006), "A Theory of Pyramidal Ownership and Family Business Groups". The Journal of Finance, 61(6), p.2637-2680.

Attílio, L. A. (2016), Empresas Não-Financeiras e o Impacto da Estratégia Maximizing Shareholder Value Sobre o Emprego no Brasil. (Dissertação de mestrado em Economia) Cedeplar/UFMG, 104p.

Becker, J.; Jager, J.; Leubolt, B. e Weissenbacher, R. (2010), "Peripheral Financialization and Vulnerability to Crisis: a regulationist perspective." Competition and Change, 14(3-4), p.225-247.

Belluzzo, L. G. e Almeida, J., (2002), Depois da Queda. Rio de Janeiro, Editora Civilização Brasileira, 412p.

Berle, A. A. e Means, G. C. (1932), The Modern Corporation and Private Property. New York: Macmillan. 332p.

Bonizzi, B. (2013), "Financialization in Developing and Emerging Countries." International Journal of Political Economy, 42(4), p.83-107.

Boyer, R. (2000), "Is a Finance-Led Growth Regime a Viable Alternative to Fordism? A Preliminary Analysis." Economy and Society, 29(1), p.111-145.

Boyer, R. (2009), Teoria da Regulação: os fundamentos. São Paulo: Estação Liberdade, 156p.

Bruno, M. e Caffé, R. (2015), "Indicadores Macroeconômicos de Financeirização: metodologia de construção e aplicação ao caso do Brasil." IN: BRUNO, M. (org.), População, Espaço e Sustentabilidade Contribuições para o desenvolvimento do Brasil. Rio de Janeiro: IBGE, p.35-61.

Bruno, M.; Diawara, H; Araújo, E.; Reis, A. C. e Rubnes M. (2011), "Finance-Led Growth Regime no Brasil: estatuto teórico, evidências empíricas e consequências macroeconômicas." Revista de Economia Política, 31(5), p.730-750. 
Cano, W. (1999), "América Latina: do desenvolvimento ao neoliberalismo." In: FIORI, J.L. (org). Estados e moedas no desenvolvimento das nações, 2. ed. Petrópolis: Vozes, p. 287 - 326.

Carneiro, R. (2002), Desenvolvimento em Crise: a economia brasileira nos último quarto do século XX. São Paulo, Editora Unesp, 423p.

Chang, Ha-Joon (2005), "Global Standards and the Future of East Asian." Global Economic Review, 34(4), p.363-378.

Chesnais, F. (1994[1996]), A Mundialização do Capital. São Paulo: Xamã Editora, 335p.

Chesnais, F. (2004[2005]), "O Capital Portador de Juros: acumulação, internacionalização, efeitos econômicos e políticos." In: F. Chesnais (org.) A Finança Mundializada, São Paulo, Editora Boi Tempo, p.35-67.

Cioffi, J. W. (2010), Public Law and Private Power: corporate governance reform in the age of finance capitalism. New York: Cornell University Press, 287p.

Coffee JR. J. C. (2001), "The Rise of Dispersed Ownership: the tole of law in the separation of ownership and control." The Yale Law Journal, 111(1), p.1-82.

Corrêa, M. F.; Lemos, P. M. e Feijó, C. (2017), "Financeirização, Firmas não financeiras e o Ciclo Econômico Recente da Economia Brasileira." In: XXII Encontro Nacional de Economia Política, Campinas, Unicamp, 25p.

Coutinho, L; Belluzzo, L. G., (2004), “"Financeirização” da riqueza, inflação de ativos e decisão de gastos em economias abertas." In: F. Ferrari Filho e L. Paula (orgs.), Globalização Financeira: ensaios de macroeconomia aberta. Petrópolis: Vozes, p.59-105.

Coutinho, L.; Rabelo, F. M., (2003), "Brazil: keeping it in the Family." In: OMAN, C. P (Org.), Corporate Governance in Development: the experiences of Brazil, Chile, India, and South Africa. OECD Development Center; Washington: Center for International Private Enterprise, p.35-75.

Crespi-Cladera, R.; Garcia-Cestona, M. A. (1999), "Ownership and Control: a Spanish survey." Working Paper, n. 23.99, 42p.

Crotty, J. (2003), "The Neoliberal Paradox: the impact of destructive product market competition and impatient finance on nonfinancial corporations in the neoliberal era." Review of Radical Political Economics, 35(3), p.271-279.

Cueto, D. C. (2013), "Substitutability and Complementarity of Corporate Governance Mechanisms in Latin America." International Review of Economic and Finance, 25, p.310325.

Davis, L. E. (2013), "Financialization and the nonfinancial corporation: an investigation of firmlevel investment behavior in the U.S., 1971-2011." Working-Paper University of Massachusetts, n. 2013-08, 25p.

Duménil, G. e Lévy, D. (2001) "Costs and Benefits of Neoliberalism. A Class Analysis." Review of International Political Economy, 8(4), p.578-607.

Evans, J.; Habbard, P. (2008), From Shareholder Value to Private Equity: the changing face of financialisation of the economy. Paris: TUAC, 13p.

Filletti, J. P. (2010), Financiamento de empresas não-financeiras de capital aberto: proposição de uma abordagem quantílica. Tese (Doutorado em Economia Aplicada) - IE, Unicamp, $156 p$. 
Flath, D. Horizontal (1992), "Shareholding Interlocks." Managerial and Decision Economics, 13(1), p.75-77.

Frenkel, R.; Fanelli, J. M. (1995), "Estabilidad y Estructura - Interacciones en el crescimento econômico." In: J. M. Katz (Org.) Estabilización macroeconômica, reforma estructural y comportamento industrial. [s.I.]: Cepal/IDRC/Aliança Editorial, p.25-41.

Friedmann, E.; Johnson, S. e Mitton, T. (2003), "Propping and Tunneling." NBER Working Paper, n. 9949, Cambridge, 40p.

Gerlach, M. L. (1992), Alliance Capitalism: the social organization of Japanese business. Berkeley University California Press, $350 \mathrm{p}$.

Gorga, E. (2009), "Changing the Paradigm of Stock Ownership from Concentrated Towards Dispersed Ownership? Evidence from Brazil and consequences for emerging countries." Northwestern Journal of International Law and Business, 29(2), p.439-551.

IBGC (2009), Código das Melhores Práticas de Governança Corporativa. Instituto Brasileiro de Governança Corporativa (IBGC), São Paulo, 72p.

Jensen, M. C. e Meckling, W. (1976), "Theory of the firm: managerial behavior, agency costs and ownership structure." Journal of Financial Economics, 3(4), p.305-360.

Johnson, S.; La Porta, R.; Lopez-De-Silanes, F. e Shleifer, A. (2000), "Tunnelling." NBER Working Paper, n.7523, 13p.

Krueger, A. O. (2002), "Why Crony Capitalism is Bad for Economic Growth." In: HABER, S. (ed.). Crony Capitalism and Economic Growth in Latin America: theory and evidence. Stanford: Hoover Institution Press. p.1-23.

La Porta, R.; Lopez-De-Silanes, F; Shleifer, A. (1999), "Corporate Ownership Around the World." The Journal of Finance, 49(2), p.471-517.

Lazonick, W. (2012), "Financialization of the U.S. Corporation: what has been lost, and how it can be regained." MPRA Paper, n. 42307, 37p.

Lazonick, W. e O'sullivan, M. (2000), “Maximizing Shareholder Value: a new ideology for corporate governance." Economy and Society, 29(1), p.13-35, 2000.

Lipietz, A. (1984), "As Transformações na Divisão Internacional do Trabalho: considerações metodológicas e esboço de teorização". Espaço e Debates, 4(12), p.66-94.

Maher, M. e Andersson, T. (1999), Corporate Governance: effects on firm performance and economic growth.[s.l.]:OECD, 51p.

Moreira, M. e Puga, F, (2001), "Como a Indústria Financia seu Crescimento? Uma Análise do Brasil Pós-Real." Revista de Economia Contemporânea, Rio de Janeiro, 5, n. especial, p.39.

OCDE (2004), OCDE Principles of Corporate Governance. Paris: OCDE, 69p.

Orhangazi, O. (2007), "Financialization and Capital Accumulation in the Non-Financial Corporate Sector: a theoretical and empirical investigation of the U.S. economy: 19732003." Working Paper, PERI, n.149, 40p.

Palley, T. (2013), Financialization: The economics of finance capital domination. Nova York, Palgrave Macmillan, 233p.

Pereira, T. R. (2000), "Formação de Preços e Financiamento Empresarial entre os anos de 80 e 90 na Economia Brasileira." Economia e Sociedade, 9(1), p.89-126. 
Plihon, D. A. (2004[2005]), "As Grandes Empresas Fragilizadas pelas Finanças." In: CHESNAIS, F. (org.) A Finança Mundializada, São Paulo, Editora Boi Tempo, p.133-151.

Prates, D. M. (1997), Abertura Financeira e Vulnerabilidade Externa a Economia Brasileira na Década de Noventa. Dissertação (Mestrado), Unicamp, Campinas, 1997, 192p.

Prowse, S. D. (1992), "The Structure of Corporate Ownership in Japan." The Journal of Finance, 47(3), p.1121-1140.

Richardson, G. B. (1972), "The Organisation of Industry." The Economic Journal, 82(32), p.883826.

Shleifer, A. e Vishny, R. W. (1996), "A Survey of Corporate Governance." NBER Working Paper, n. 5554, Cambridge, 1996. 69p.

Singh, A. (1995), "Corporate Financial Patterns in Industrializing Economies." International Finance Corporation, Washington: Technical Paper, n. 2, 75p.

Singh, A.; Singh, A.; Weisse, B. (2002), "Corporate Governance, Competition, the New International Financial Architecture and Large Corporations in Emerging Markets." ESRC Working Paper, University of Cambridge, n.250, p.68.

Siqueira, T. V. (1998), "Concentração de Propriedade nas Empresas Brasileiras de Capital Aberto." Revista do BNDES, Rio de Janeiro, 24p.

Stockhammer, E. (2004), "Financialization and the Slowdown of Accumulation." Cambridge, 28(5), p.719-741.

Stockhammer, E. (2010), "Financialization and the Global Economy." UMASS Working Paper Series, n. 240, 17p.

Tavares, M. C. e Melin, L. E. (1998), "Pós-escrito 1997: a reafirmação da economia americana." In: Tavares, M. C.; FIORI, J. L. (Org.). Poder e Dinheiro: uma economia política da globalização. São Paulo, Editora Vozes, p.55-86.

Thomsen, S.; Pedersen, T. (1997), "European Ownership Concentration: causes and consequences." Working Paper, Frederiksberg: Institute of International Economics and Management, p. 97.

Weib, C. (2010), The Ownership Concentration of Firms: three essays on the determinants and effects. Tese (doutorado), European Business School, 164p. Disponível em: http://hdl.handle.net/10419/30247.

Williamson, O. (1985), The Economic institutions of capitalism: firms, markets, relational contracting. New York: The Free Press.

Wolfenzon, D. A. (1999), "Theory of Pyramidal Ownership." Havard University Working Paper, Chicago, 1999. 46p.

Zonenschain, C. N. (1998), "Estrutura de Capital das Empresas no Brasil." Revista do BNDES, Rio de Janeiro, 5(10), 23p. 